\title{
Reply to Letter to the Editor: "The added benefit of contrast-enhanced CT in the evaluation of incidental FDG-avid colon lesions"
}

\author{
Julian Kirchner ${ }^{1}$ - Benedikt M. Schaarschmidt ${ }^{1} \cdot$ Firas Kour $^{1} \cdot$ Lino M. Sawicki ${ }^{1} \cdot$ Ole Martin $^{1} \cdot$ Johannes Bode $^{2}$. \\ Stephan vom Dahl $^{2} \cdot$ Verena Keitel $^{2} \cdot$ Dieter Häussinger $^{2} \cdot$ Christina Antke $^{3} \cdot$ Christian Buchbender $^{1} \cdot$ Gerald Antoch $^{1}$. \\ Philipp Heusch ${ }^{1}$
}

Published online: 30 June 2020

(C) The Author(s) 2020

We would like to thank Dr. Lee and colleagues for their well-thought-out questions and their interest in our work about the added benefit of contrast-enhanced $\mathrm{CT}$ in the evaluation of incidental FDG-avid colonic lesions [1].

First, while an overall incidence of focal ${ }^{18}$ F-FDG uptake in the colon has been observed in 1.3-3\% [2-7] in the studies mentioned by Dr. Lee and colleagues, focal tracer uptake was detected in $38.4 \%$ in our cohort. Taking a closer look at the results, this difference is probably due to a different reference standard. All studies mentioned by Dr. Lee and colleagues calculated the incidence based on the total sum of all PET/CT examinations performed. Our study only included patients who had undergone contrast-enhanced ${ }^{18} \mathrm{~F}$-FDG PET/CT and colonoscopy within 6 months after PET/CT. Compared with a nonselected patient population, the population in our study can, thus, be expected to have a higher incidence of colon

This article is part of the Topical Collection on Oncology Digestive tract

This Letter to the editor and reply refers to the article https://doi.org/10. 1007/s00259-020-04716-y

Julian Kirchner

Julian.Kirchner@med.uni-duesseldorf.de

1 Department of Diagnostic and Interventional Radiology, Medical Faculty, University Dusseldorf, Moorenstrasse 5,

D-40225 Düsseldorf, Germany

2 Clinic for Gastroenterology, Hepatology and Infectious Diseases, University Hospital Düsseldorf, Medical Faculty,

Heinrich-Heine-University, Moorenstrasse 5, 40225 Düsseldorf, Germany

3 Medical Faculty, Department of Nuclear Medicine, University Dusseldorf, 40225 Düsseldorf, Germany pathology. This issue has been addressed in Discussion. Assessment for focal colonic ${ }^{18} \mathrm{~F}$-FDG uptake was performed based on only the PET dataset; thus, the CT component had no influence on the incidence.

Second, in our study, the positive predictive value (PPV) was increased from 29 to $50 \%$ by including CT findings (wall-thickening, intraluminal nodule, and contrast enhancement). To our opinion, similar PPVs in the studies cited by Dr. Lee and colleagues may also be explained by difference in patient populations. In the study by Gutman et al., the PPV was $67 \%$, but was calculated for all coloscopic abnormalities and included adenomas with mild to moderate dysplasia [4]. In the study by Lee et al., every type of adenoma was defined as pre-malignant [7], while in our study, adenomas without or with low-grade intraepithelial neoplasias were excluded, as they do not have clinical impact. The PPV given in the study of Israel et al. (46\%) was calculated for the whole GIT; results for findings only in the colon are not given in this paper [5]. The highest PPV was reported by Even-Sapir et al. However, this study design aimed at the evaluation of malignant colonic tumours and pre-malignant lesions rather than all incidentally found lesions [3]. Only proven malignancies were included in the final analysis and even FDG-PET-negative masses detected on CT.

Funding Information Open Access funding provided by Projekt DEAL.

\section{Compliance with ethical standards}

Informed consent Not applicable.

Ethical approval Institutional Review Board approval does not apply because the paper is an Editorial. 
Conflict of interest The authors declare that they have no conflict of interest.

Open Access This article is licensed under a Creative Commons Attribution 4.0 International License, which permits use, sharing, adaptation, distribution and reproduction in any medium or format, as long as you give appropriate credit to the original author(s) and the source, provide a link to the Creative Commons licence, and indicate if changes were made. The images or other third party material in this article are included in the article's Creative Commons licence, unless indicated otherwise in a credit line to the material. If material is not included in the article's Creative Commons licence and your intended use is not permitted by statutory regulation or exceeds the permitted use, you will need to obtain permission directly from the copyright holder. To view a copy of this licence, visit http://creativecommons.org/licenses/by/4.0/.

\section{References}

1. Kirchner J, Schaarschmidt BM, Kour F, et al. Incidental (18)F-FDG uptake in the colon: value of contrast-enhanced CT correlation with colonoscopic findings. Eur J Nucl Med Mol Imaging. 2019.
2. Agress H Jr, Cooper BZ. Detection of clinically unexpected malignant and premalignant tumors with whole-body FDG PET: histopathologic comparison. Radiology. 2004;230(2):417-22.

3. Even-Sapir E, Lerman H, Gutman M, et al. The presentation of malignant tumours and pre-malignant lesions incidentally found on PET-CT. Eur J Nucl Med Mol Imaging. 2006;33(5):541-52.

4. Gutman F, Alberini JL, Wartski M, et al. Incidental colonic focal lesions detected by FDG PET/CT. AJR Am J Roentgenol. 2005;185(2):495-500.

5. Israel $\mathrm{O}$, Yefremov $\mathrm{N}$, Bar-Shalom R, et al. PET/CT detection of unexpected gastrointestinal foci of 18F-FDG uptake: incidence, localization patterns, and clinical significance. J Nucl Med. 2005;46(5):758-62.

6. Kamel EM, Thumshirn M, Truninger K, et al. Significance of incidental 18F-FDG accumulations in the gastrointestinal tract in PET/ CT: correlation with endoscopic and histopathologic results. J Nucl Med. 2004;45(11):1804-10.

7. Lee JC, Hartnett GF, Hughes BG, Ravi Kumar AS. The segmental distribution and clinical significance of colorectal fluorodeoxyglucose uptake incidentally detected on PET-CT. Nucl Med Commun. 2009;30(5):333-7.

Publisher's note Springer Nature remains neutral with regard to jurisdictional claims in published maps and institutional affiliations. 